\title{
Gallbladder Papillary Neoplasm
}

National Cancer Institute

\section{Source}

National Cancer Institute. Gallbladder Papillary Neoplasm. NCI Thesaurus. Code C7130.

A non-invasive, papillary epithelial neoplasm that arises from the epithelium of the gallbladder. Intraepithelial neoplasia is present. 